Artikel Penelitian

\title{
PENGUATAN PENDIDIKAN KARAKTER MELALUI PEMBELAJARAN SEJARAH BERBASIS KITAB KUNTARA RAJA NITI
}

\author{
Andika Dian Ifti Utami, Warto, Sariyatun \\ Pascasarjana Pendidikan Sejarah, Universitas Sebelas Maret
}

\begin{abstract}
This study aims to strengthen the character of the students so that they have a national identity. Strengthening of character in society can be built through the utilization of local history which have moral values. Historical sources such as Kitab Kuntara Raja Niti contains values that are believed to create an attitude of peace, friendship, responsibility, tolerance, the spirit of nationalism, care for the environment, social care, religious, recognize excellence, independence and discipline. The importance of this study is based on the assumption that cultural heritage is an educational component that can foster a sense of belonging and respect their own cultural history. Kitab Kuntara Raja Niti consist of ideas and guidance of mankind's relationship with God, the community and the natural environment that can be a filter to face of global cultural transformation and play a role in strengthening national identity. So that these values are very relevant to be taken in history as character education for students. This study uses a qualitative method, by collecting documents related to the Kitab Kuntara Raja Niti either Indigenous Book, Journal, Manuscripts-Manuscripts or other documents relating to the object, and then analyzed through descriptive approach.
\end{abstract}

Key words: Character Education, Kitab Kuntara Raja Niti, Learning History

\section{PENDAHULUAN}

Melihat kondisi Indonesia yang multikultural membuat masyarakatnya hidup dalam keberagaman. SARA (suku, agama, ras, dan antargolongan) sering menjadikan adanya gesekan, silang budaya antara satu suku atau agama dengan suku atau agama yang lain. Kasus yang menonjol adalah konflik antar etnis di Lampung yang tergolong dalam konflik besar adalah (1) Pembakaran Pasar Purbolinggo di Lampung Timur oleh etnis Bali pada tahun 2010, (2) Bentrokan antara etnis Jawa dan Bali melawan etnis Lampung pada 29 Desember 2010 di Lampung Tengah yang di latar belakangi oleh pencurian ayam, (3) Bentrokan etnis Jawa melawan etnis Lampung pada September 2011 di Sidomulyo Lampung Selatan yang dilatar belakangi oleh sengketa pengelolaan lahan parkir, dan (4) Bentrokan antar etnis Bali dan etnis Lampung pada Januari 2012 disusul dengan bentrokan kedua di Sidomulyo Lampung Selatan pada Oktober 2012 (Wahyu, 2016).

JPSI, Vol. 1, No., 1, 2018 
Konflik antar etnis yang terjadi di Lampung seringkali di sebabkan oleh permasalahan sederhana antar individu yang berbeda etnis namun pada akhirnya melibatkan anggota kelompok antar etnis. Untuk itu, diiperlukan suatu pendidikan yang berorientasi dan bertujuan untuk menyatukan kehidupan berban gsa sesuai amanah yang tercantum dalam pembukaan Undang-Undang Dasar 1945. Undang-Undang Nomor 20 tahun 2003 tentang Sistem Pendidikan Nasional (Kemdiknas) pasal 3 menegaskan, bahwa "pendidikan nasional berfungsi mengembangkan kemampuan dan membentuk watak serta peradaban bangsa yang bermartabat dalam rangka mencerdaskan kehidupan bangsa, bertujuan untuk berkembangnya potensi peserta didik agar menjadi manusia yang beriman dan bertakwa kepada Tuhan Yang Maha Esa, berakhlak mulia, sehat, berilmu, cakap, kreatif, mandiri, dan menjadi warga negara yang demokratis serta bertanggungjawab". Oleh karena itu, pendidikan merupakan alat yang digunakan untuk membentuk karakter setiap manusia secara utuh sehingga memunculkan karakter bangsa. Pendidikan juga harus membangun manusia secara utuh yang berkarakter, tidak hanya beriman dan bertaqwa, tetapi juga memiliki toleransi serta wawasan kebangsaan yang kuat.

Karakter sangat erat hubungannya dengan budaya, kebiasaan, sistem nilai dan norma yang berlaku dalam lingkungan masyarakat. Hakikat pendidikan karakter di Indonesia adalah pendidikan nilai, yaitu pendidikan nilai yang luhur yang bersumber dari karakter bangsa Indonesia itu sendiri (Fathurrohman, 2013: 15). Pendidikan karakter bisa didapatkan dari segala sesuatu yang dilakukan oleh guru yang mampu mempengaruhi karakter peserta didik, termasuk melalui pembelajaran sejarah. Pembelajaran sejarah dalam fungsi edukatif berguna sebagai wisdom yakni sering disebut sebagai kearifan atau kebijaksanaan (Notosusanto, 1979: 5). Mempelajari sejarah pada prinsipnya adalah memahami gagasan-gagasan atau analisis dibalik peristiwa. Bagaimana memanfaatkan data dan menghidupkanya menjadi memori sejarah. Sejarah mengajarkan kepada kita tentang perbuatan manusia dimasa lampau.

Melalui pembelajaran sejarah guru dapat membentuk karakter dan membangun moral peserta didik melalui peristiwa-peristiwa, karakter-karakter tokoh, dan fakta-fakta dalam sejarah. Pembelajaran sejarah memiliki arti penting dalam pembentukan watak serta membentuk moral peserta didik sehingga mereka diharapkan kedepan menjadi benteng-benteng yang kokoh dengan semangat nasionalismenya (Wahyudi dalam Widiadi, 2013: 25). Sumber sejarah lokal seperti Kitab Kuntara Raja Niti diperlukan untuk menguatkan karakter siswa serta menghindarkan siswa tidak tahu nilai sejarah yang ada di sekitarnya. Untuk itu, penulis dalam artikel ini membahas nilai-nilai Kitab Kuntara Raja 
Niti yang dapat diinternalisasikan dalam pembelajaran sejarah sebagai penguat pendidikan karakter.

\section{METODE}

Pendekatan penelitian tersebut adalah kualitatif deskriptif dengan memanfaatkan dokumentasi untuk menghimpun informasi yang relevan yang berkaitan dengan masalah yang diteliti. (Sugiyono, 2014: 82) mengatakan bahwa dokumen adalah catatan peristiwa yang sudah lalu. (Sugiyono, 2014: 144) menyimpulkan metode kepustakaan merupakan suatu metode pengumpulan data dengan berdasarkan buku-buku dan sumber tertulis yang berkaitan dengan masalah yang diteliti. Untuk menganalisis data yang telah diperoleh maka peneliti melakukan analisis data melalui strategi analisa data kualitatif. Penelitian dilakukan untuk memperoleh gambaran umum yang menyeluruh tentang situasi sosial yang diteliti atau objek penelitian.

Data yang diperoleh dari lapangan dilakukan analisis data melalui reduksi data kemudian peneliti melakukan penyajian data dengan uraian singkat, bagan, hubungan antar kategori dan data senantiasa diuji sebab data yang berlangsung di lapangan akan mengalami perkembangan. Langkah selanjutnya penarikan kesimpulan awal yang dikemukakan akan bersifat sementara dan akan berubah bila tidak ditemukan bukti-bukti yang kuat yang mendukung pada tahap pengumpulan data berikutnya. Penulis melalukukan uji keabsahan hasil penelitian dengan melakukan triangulasi sumber data dengan mengacu kepada Denzin (dalam Bungin, 2010: 264) maka pelaksanaan teknis dari langkah pengujian keabsahan data akan memanfaatkan sumber, metode dan teori.

\section{HASIL DAN PEMBAHASAN}

\section{PENDIDIKAN KARAKTER}

Kamus umum bahasa Indonesia menyatakan bahwa, karakter adalah sifat-sifat kejiwaan, akhlak atau budi pekerti yang membedakan seseorang dengan yang lain. Pendidikan karakter adalah suatu sistem penanaman nilai-nilai karakter kepada siswa atau warga sekolah yang meliputi komponen pengetahuan, kesadaran atau kemauan, dan tindakan untuk melaksanakan nilai-nilai tersebut (Harsojo, 2013: 21). Pendidikan karakter menjadi gerakan nasional dalam sekolah sebagai agen untuk membangun karakter peserta didik melalui pembelajaran. 
Pendidikan karakter menanamkan kebiasaan (habituation) tentang yang baik sehingga peserta didik paham, mampu merasakan, dan mau melakukan yang baik (Marzuki, 2012: 37). Pendidikan karakter juga memiliki esensi dan makna yang sama dengan pendidikan moral dan pendidikan akhlak (Ramli dalam fathurrohman, 2003: 15). Berdasarkan pengertian tersebut maka dapat disimpulkan bahwa pendidikan karakter merupakan upaya penyiapan kekayaan batin siswa dengan dimensi agama, sosial, budaya dan mampu mewujudkan dalam bentuk budi pekerti, baik dalam perbuatan, perkataan, pikiran, sikap, perasaan dan kepribadian.

Pendidikan karakter dimaksudkan untuk mengembangkan kemampuan dan membentuk watak serta peradaban bangsa yang bermartabat dalam rangka mencerdaskan kehidupan bangsa. Tujuannya adalah membentuk pribadi siswa, supaya menjadi manusia yang baik, warga masyarakat yang baik, dan warga Negara yang baik. Adapun kriteria manusia yang baik, warga masyarakat yang baik, dan warga negara yang baik bagi suatu masyarakat atau bangsa, secara umum adalah nilai-nilai sosial tertentu yang banyak dipengaruhi oleh budaya masyarakat dan bangsanya. Selain itu, pendidikan karakter adalah segala sesuatu yang dilakukan oleh guru atau pendidik untuk mempengaruhi karakter siswa. Guru membantu dalam membentuk karaker siswa dengan cara memberikan keteledanan, cara berbicara atau menyampaikan materi yang baik, toleransi, dan berbagai hal yang terkait lainnya (Asmani, 2012: 31).

Pentingnya pendidikan karakter untuk segera dikembangkan dan diinternalisasikan, baik dalam dunia pendidikan formal maupun dalam pendidikan non formal tentu beralasan, karena memiliki tujuan yang cukup mulia bagi bekal kehidupan peserta didik agar senantiasa siap dalam merespon segala dinamika kehidupan dengan penuh tanggung jawab. Ada enam pilar penting untuk mengukur dan menilai watak atau perilakunya, yaitu: Respect atau penghormatan, Responsibility atau tanggungjawab, Citizenship-Civic Duty atau kesadaran berwarganegara, Fairness atau keadilan, Caring atau kepedulian, dan Tustworhiness atau kepercayaan (Fathurrohman, 2013: 19). Pilar-pilar tersebut dapat dijadikan acuan guru sebagai penilaian karakter siswa. Selain itu terdapat delapan belas nilai-nilai dalam pendidikan karakter menurut Diknas adalah (Fathurrohman, 2013: 19):

1. Religius

Sikap dan perilaku yang patuh dalam melaksanakan ajaran agama yang dianutnya, toleran terhadap pelaksanaan ibadah agama lain, dan hidup rukun dengan pemeluk agama lain.

2. Jujur

JPSI, Vol. 1, No., 1, 2018 
Perilaku yang didasarkan pada upaya menjadikan dirinya sebagai orang yang selalu dapat dipercaya dalam perkataan, tindakan, dan pekerjaan.

3. Toleransi

Sikap dan tindakan yang menghargai perbedaan agama, suku, etnis, pendapat, sikap, dan tindakan orang lain yang berbeda dari dirinya.

4. Disiplin

Tindakan yang menunjukkan perilaku tertib dan patuh pada berbagai ketentuan dan peraturan.

5. Kerja Keras

Tindakan yang menunjukkan perilaku tertib dan patuh pada berbagai ketentuan dan peraturan.

6. Kreatif

Berpikir dan melakukan sesuatu untuk menghasilkan cara atau hasil baru dari sesuatu yang telah dimiliki.

7. Mandiri

Sikap dan perilaku yang tidak mudah tergantung pada orang lain dalam menyelesaikan tugas-tugas.

8. Demokratis

Cara berfikir, bersikap, dan bertindak yang menilai sama hak dan kewajiban dirinya dan orang lain.

9. Rasa Ingin Tahu

Sikap dan tindakan yang selalu berupaya untuk mengetahui lebih mendalam dan meluas dari sesuatu yang dipelajarinya, dilihat, dan didengar.

10. Semangat Kebangsaan

Cara berpikir, bertindak, dan berwawasan yang menempatkan kepentingan bangsa dan negara di atas kepentingan diri dan kelompoknya.

11. Cinta Tanah Air

Cara Berpikir, bertindak, dan berwawasan yang menempatkan kepentingan bangsa dan negara di atas kepentingan diri dan kelompoknya.

12. Menghargai Prestasi

Sikap dan tindakan yang mendorong dirinya untuk menghasilkan sesuatu yang berguna bagi masyarakat, dan mengakui, serta menghormati keberhasilan orang lain.

13. Bersahabat/Komunikatif

JPSI, Vol. 1, No., 1, 2018 
Sikap dan tindakan yang mendorong dirinya untuk menghasilkan sesuatu yang berguna bagi masyarakat, dan mengakui, serta menghormati keberhasilan orang lain.

14. Cinta Damai

Sikap dan tindakan yang mendorong dirinya untuk menghasilkan sesuatu yang berguna bagi masyarakat, dan mengakui, serta menghormati keberhasilan orang lain.

15. Gemar Membaca

Kebiasaan menyediakan waktu untuk membaca berbagai bacaan yang memberikan kebajikan bagi dirinya.

16. Peduli Lingkungan

Sikap dan tindakan yang selalu berupaya mencegah kerusakan pada lingkungan alam di sekitarnya, dan mengembangkan upaya-upaya untuk memperbaiki kerusakan alam yang sudah terjadi.

17. Peduli Sosial

Sikap dan tindakan yang selalu ingin memberi bantuan pada orang lain dan masyarakat yang membutuhkan.

18. Tanggung Jawab

Sikap dan perilaku seseorang untuk melaksanakan tugas dan kewajibannya, yang seharusnya dia lakukan, terhadap diri sendiri, masyarakat, lingkungan (alam, sosial dan budaya), negara dan Tuhan Yang Maha Esa.

\section{KITAB KUNTARA RAJA NITI}

Kitab Kuntara Raja Niti merupakaan naskah kuno Lampung yang menjelaskan tentang adat istiadat, kesenian, sejarah Lampung dan lain-lain. Kitab Kuntara Raja Niti digunakan disetiap suku Lampung baik pepadun maupun pesisir (Syahrul, 2011: 8). Aturan adat tersebut merupakan tradisi budaya yang penuh dengan berbagai kearifan sebagai cerminan pandangan hidup orang Lampung sejak masa lampau. Kitab Kuntara Raja Niti berupa manuskrip Lampung yang ditulis oleh setiap kepala adat atau pemangku adat, dimana Kitab Kuntara Raja Niti tersebut merupakan suatu warisan kebudayaan yang secara nyata memberikan bukti catatan tentang kebudayaan masa lalu dan masih dapat digunakan hingga sekarang. Hal tersebut dapat dikaitkan dengan hasil penelitian bahwa, "Kitab Kuntara Raja Niti adalah Kitab yang berisi tuntutan moral yang menjadi pedoman masyarakat Lampung" (Irianto, 2011: 143). Karya-karya tulisan masa lampau 
perlu dipelajari sebab didalamnya terkandung nilai-nilai yang masih relevan dengan kehidupan masa kini (Baried, 1994: 1).

Tebal Kitab Kuntara Raja Niti XV Bab dengan pasal 226 (Hilman, 1986: 1). Bahasan dalam Kitab Kuntara Raja Niti yaitu Bab 1 baik buruknya kampung, Bab 2 petugas dan penyimbang, Bab 3 bujang dan gadis, Bab 4 pembantu dan wanita, Bab 5 panggalaku, Bab 6 piil pesenggiri, Bab 7 kaganga kesalahan, Bab 8 perjanjian perkawinan, Bab 9 kesalahan lanjutan, Bab 10 jatuhnya martabat adat, Bab 11 jatuhnya nilai pribadi, Bab 12 beberapa kesalahan tambahan, Bab 13 tata tertib adat pepadun, Bab 14 keturunan batin telu suku dan bab 15 kesepakatan batin telu suku. Kitab Kuntara Raja Niti disimpan dikediaman pemangku adat dari setiap keturunan dan disampaikan turun temurun secara lisan. Berdasarkan hal tersebut dapat dipahami bahwa Kitab Kuntara Raja Niti merupakan kitab rujukan ulun (masyarakat) Lampung yang mengatur tentang tata cara hidup bermasyarakat.

Ajaran kesadaran budaya dalam kehidupan masyarakat membahas tentang apa yang harus disiapkan untuk generasi muda ketika mereka sudah dewasa dan menjalin kehidupan keluarga, tetangga dan bermasyarakat. Berikut pedoman yang harus dipahami oleh masyarakat (Wahyu. E, 2013: 21) yaitu:

1. Senang negeri mengajarkan tentang cinta damai, bersahabat dan tanggungjawab. Dalam kitab Kuntara Raja Niti disebutkan "Senang negeri: (1) Cawa sepuluh sudi cukup, (2) Muli meranai lamon sai ranta sapun, (3) Raji ni sabar, dan (4) Anak buwah maka kakira." Arti ungkapan tersebut adalah sebagai berikut: Senangnya negeri: (1) Berbicara sepuluh kata sudah cukup, (2) Bujang gadisnya sopan santun, (3) Rajanya sabar, dan (4) Anak buah dalam menggunakan barang dengan hati-hati.

2. Ganjaran bator mengajarkan tentang toleransi, semangat kebangsaan, cinta tanah air, peduli lingkungan dan peduli sosial. Dalam kitab Kuntara Raja Niti disebutkan "Ganjaran bator: (1) ngangas ngudut punyimbang ni mak kurang, (2) Punyimbang ni mak peros hati dilom tiyuh hon, dan (3) Punyimbang ni hipal wat ubat ni diya layin dua ulah bator ni diya." Arti ungkapan tersebut adalah sebagai berikut: Malunya pemimpin: (1) Sirih dan rokok penyimbang tidak kurang, (2) Penyimbang tidak asem hati saat ada hajatan, dan (3) Penyimbang tidak membuat masalah dikampung lain.

3. Ganjaran bubai punyimbang mengajarkan tentang religius, menghargai prestasi, mandiri dan disiplin. Kitab Kutara Raja Niti menyebutkan "Ganjaran bubai punyimbang: (1) adik waari ni mak sungkan reti da hati ni tandok, (2) badan sekelik ni pagun ngerim reli hakal ning tagom, (3) Jenganan ni rajin rati hati ni mukmin, (4) Temui ni mak silip, (5) Punguten ni mak kurang rang, dan (6) hati ga pagor ni lapang." 
Arti kutipan tersebut sebagai berikut: Malunya istri pemimpin: (1) saudarasaudaranya tidak segan dan hatinya baik, (2) Saling menasehati dan pintar, (3) Rumahnya rajin dan hatinya baik, (4) baik dan perhatian terhadap tamu, (5) Ruangan tempat berkumpul luas dan (6) hatinya selalu lapang.

Ajaran dalam Kitab Kuntara Raja Niti Tersebut relevan dengan kehidupan masyarakat saat ini. Karakter siswa akan kuat di masa depan, karakter di sini dimaksudkan bahwa siswa lebih memiliki sikap cinta damai, bersahabat, tanggung jawab, toleransi, semangat kebangsaan, cinta tanah air, peduli lingkungan, peduli sosial, religius, menghargai prestasi, mandiri dan disiplin.

\section{PEMBELAJARAN SEJARAH}

Pembelajaran menurut Brown (dalam Suranto, 2015: 127) merupakan proses interaktif melalui pengetahuan dan keterampilan yang dibagi bersama siswa dengan tujuan agar para siswa meningkatkan pemahaman dan memiliki kemampuan untuk memanipulasi kehidupan sosial, ekonomi, politik, dan lingkungan fisik sehingga mereka dapat eksis atau bertahan hidup (survive). Selain itu Menurut Piaget (dalam Dimyati dan Mudjiono, 2013: 14) pembelajaran terdiri dari empat langkah, yaitu: (1) menentukan topik yang dapat dipelajari oleh anak sendiri; (2) memilih atau mengembangkan aktivitas kelas dengan topik tersebut; (3) mengetahui adanya kesempatan guru untuk mengemukakan pertanyaan yang menunjang proses pemecahan masalah; dan (4) menilai pelaksanaan kegiatan, memperhatikan keberhasilan, dan melakukan revisi. Secara singkat dalam pembelajaran guru memilih masalah yang berciri kegiatan prediksi, eksperimentasi, dan eksplanasi.

Guru dalam proses pembelajaran merupakan fasilitator yang mengarahkan siswa agar dapat memahami sebuah masalah pada topik yang telah ditentukan, serta menilai setiap kegiatan yang terjadi dalam proses pembelajaran. Peran guru dalam membimbing proes pembelajaran sangat penting. Pembelajaran yang berlangsung adalah sebuah proses penemuan oleh siswa namun dengan pengarahan atau guru sebagai fasilitator, sehingga tujuan yang diharapkan akan tercapai dalam proses pembelajaran.

Dijelaskan dalam Permendiknas No. 22 Tahun 2006 tentang standar isi untuk satuan pendidikan dasar dan menengah bahwa sejarah merupakan cabang ilmu pengetahuan yang menelaah tentang asal usul dan perkembangan serta peran masyarakat di masa lampau berdasarkan metode dan metodologi tertentu. Pembelajaran sejarah seharusnya dapat menjadi suatu pembelajaran yang imajinatif yang akan mempunyai banyak 
manfaat dalam kehidupan bangsa. Pembelajaran sejarah seharusnya mampu menjadi pengikat konstruksi nasionalisme bangsa Indonesia. Bukan hanya sekedar menghafal fakta, pembelajaran sejarah pada umumnya mempunyai beberapa manfaat dalam menanamkan nasionalisme.

Senada dengan hal tersebut, (Agung \& Wahyuni, 2013: 55) menegaskan bahwa sejarah adalah mata pelajaran yang menanamkan sikap, pengetahuan, dan nilai-nilai mengenai proses perubahan dan perkembangan masyarakat Indonesia dan dunia dari masa lampau hingga kini. Kemudian pengajaran sejarah di sekolah bertujuan agar siswa memperoleh kemampuan berpikir historis dan pemahaman sejarah. Melalui pengajaran sejarah, siswa mampu membangun kompetensi untuk berpikir secara kronologis dan memiliki pengetahuan tentang masa lampau yang dapat digunakan untuk memahami dan menjelaskan proses perkembangan dan perubahan masyarakat serta keragaman sosial budaya dalam rangka menemukan dan menumbuhkan jati diri bangsa di tengah-tengah kehidupan masyarakat dunia.

\section{PENGUATAN KARAKTER SISWA MELALUI PEMBELAJARAN SEJARAH BER- BASIS KITAB KUNTARA RAJA NITI}

Berdasarkan pembahasan di atas dapat ditegaskan bahwa pendidikan karakter merupakan upaya-upaya yang dirancang dan dilaksanakan secara sistematis untuk membantu generasi muda memahami nilai-nilai perilaku manusia yang berhubungan dengan Tuhan Yang Maha Esa, diri sendiri, sesama manusia, lingkungan, dan kebangsaan yang terwujud dalam pikiran, sikap, perasaan, perkataan, dan perbuatan berdasarkan normanorma agama, hukum, tata krama, budaya, dan adat istiadat. Karakter yang baik terdiri atas proses-proses yang meliputi, mengetahui mana yang baik (knowing the good), keinginan melakukan yang baik (desiring the good), dan melakukan yang baik (doing the good). Menurut Ramli (dalam Gunawan, 2014: 24) menjelaskan bahwa pendidikan karakter memiliki esensi dan makna yang sama dengan pendidikan moral dan pendidikan akhlak.

Kitab Kuntara Raja Niti dalam pendidikan karakter pada dasarnya berisi nilai-nilai moral yang dikelompokkan kedalam nilai-nilai inti seperti nilai moralitas, nilai sosial, dan nilai religiusitas. Nilai moral adalah aspek-aspek yang berkembang pada diri individu melalui interaksi antara aktivitas internal dan pengaruh stimulus eksternal. Pada awalnya seorang anak belum memiliki nilai-nilai dan pengetahuan mengenai nilai moral tertentu 
atau tentang apa yang dipandang baik atau tidak baik oleh kelompok sosialnya. Selanjutnya, dalam berinteraksi dengan lingkungan, anak mulai belajar mengenai berbagai aspek kehidupan yang berkaitan dengan nilai moral (Mohammad Ali \& Asrori, 2012: 146). Sekolah-sekolah tersebut harus menyediakan lingkungan moral yang menekankan nilainilai baik dan menempatkannya di barisan depan kesadaran setiap orang.

Proses penguatan karakter pada siswa yaitu dilakukan dengan menginternalisasikan nilai-nilai Kitab Kuntara Raja Niti dalam pembelajaran sejarah di kelas. Melalui internalisasi nilai-nilai Kitab Kuntara Raja Niti dalam pembelajaran sejarah yang diterapkan secara kelompok pada ranah kognitif, maka siswa dapat berinteraksi, menerima dan berbagi pengetahuan tanpa melihat suku, status sosial, adat dan agama. Selain itu, siswa dilatih untuk memiliki sikap cinta damai, bersahabat, tanggungjawab, toleransi, semangat kebangsaan, cinta tanah air, peduli lingkungan, peduli sosial, religius, menghargai prestasi, mandiri dan disiplin. Sikap tersebut masuk dalam bagian pendidikan karakter yang dapat diklasifikasikan sebagai etika pribadi.

Proses internalisasi dalam pembelajaran sejarah dilakukan oleh guru dengan cara guru memasukkan nilai-nilai Kitab Kuntara Raja Niti kedalam materi sejarah yang akan diajarkan. Pengajaran akan lebih menarik apabila guru mengajak siswa untuk memahami nilai-nilai Kitab Kuntara Raja Niti yang dapat diteladani dan harus dihindari dari materi pelajaran yang didiskusikan. Penyampaian materi sejarah dapat dilakukan dengan mengkaitkan keadaan sekarang. Misalnya saja guru dengan memberikan contoh positif dan negatif mengenai karakter-karakter yang dimiliki pemimpin- pemimpin negara atau pejabat-pejabat negara pada saat ini.

Contoh positif ada banyak pemimpin dan pejabat negara yang mempunyai karakter baik dengan berdedikasikan dirinya untuk kepentingan bangsa dan negaranya. Sedangkan untuk yang negatif dapat diberikan contoh pemimpin atau pejabat negara yang melakukan korupsi. Lebih nyata lagi nilai-nilai karakter tersebut dapat diaplikasikan dalam kehidupan siswa disekolah misalnya dalam oraganisasi seperti OSIS, pramuka dan lainnya atau dalam lingkungan masyarakatnya seperti Karang Taruna dan perkumpulan pemuda lainnya. Diharapkan peserta didik dapat menjadi agen perubahan di dalam masyarakatnya.

\section{SIMPULAN}

Berdasarkan telaah diatas dapat disimpulkan bahwa nilai-nilai Kitab Kuntara Raja Niti penting untuk menguatkan karakter siswa sehingga siswa memiliki jati diri bangsa. 
Sistem nilai mempunyai hubungan yang erat dengan kebudayaan. Penguatan karakter siswa melalui pembelajaran sejarah berbasis Kitab Kuntara Raja Niti diperlukan untuk mengajarkan siswa tentang sikap cinta damai, bersahabat, tanggungjawab, toleransi, semangat kebangsaan, cinta tanah air, peduli lingkungan, peduli sosial, religius, menghargai prestasi, mandiri dan disiplin. Nilai-nilai Kitab Kuntara Raja Niti dalam pembelajaran sejarah diperlukan dalam upaya menggugurkan anggapan bahwa sejarah adalah pembelajaran yang membosankan dan kurang bermanfaat bagi siswa. Selain itu, Kitab Kuntara Raja Niti sebagai budaya lokal dapat menjadi benteng dalam menghadapi transformasi budaya global dan berperan dalam menguatkan jati diri bangsa.

Nilai-nilai karakter yang terkandung dalam Kitab Kuntara Raja Niti diinternalisasikan dalam pembelajaran sejarah dikelas. Materi di dalam pembelajaran sejarah dapat dikembangkan untuk melatih keterampilan berpikir siswa agar mampu untuk berpikir kritis, analisis dan kreatif sehingga mampu menumbuh kembangkan rasa patriotisme untuk kemajuan. Selain itu, internalisasi nilai Kitab Kuntara Raja Niti dalam pembelajaran sejarah dapat lebih mengenalkan peserta didik tentang sejarah daerahnya, sehingga membuat peserta didik untuk lebih tertarik.

\section{RUJUKAN}

Agung, L.S \& Wahyuni, S. 2013. Perencanaan Pembelajaran Sejarah. Yogyakarta: Ombak. Ali, Mohammad \& Asrori. 2012. Psikologi Remaja: Perkembangan Peserta Didik. PT Bumi Aksara: Jakarta.

Asmani, J. M. 2012. Buku Panduan Internalisasi Pendidikan Karakter Di Sekolah. Yogyakarta: Diva Press.

Baried, S. B. 1994. Pengantar Teori Filologi. Universitas Gajah Mada: Fakultas Sastra.

Bungin, B. 2010. Penelitian Kualitatif. Jakarta: Putra Grafika.

Dimyati dan Mudjiono. 2013. Belajar dan Pembelajaran. Jakarta : Rineka Cipta.

Fatthurrohman, P., Suryana., Fatriani, F. 2013. Pengembangan Pendidikan Karakter. Bandung: PT Refika Aditama.

Gunawan, H. 2014. Pendidikan Karakter: Konsep dan Implementasi. Bandung: ALFABETA. Harsojo, A. 2013. Membangun Karakter Berkearifan Lokal dalam Bingkai Pendidikan Persekolahan. Jurnal Pelopor Pendidikan. 4 (1). 19-28.

Hilman, H. 1986. Kuntara Raja Niti. Lampung: Tanpa Penerbit. 
Irianto, S, \& Margaretha, R. 2011. Piil Pesenggiri: Modal Budaya dan Strategi Identitas Ulun Lampung. Jurnal MAKARA Sosial Humaniora, 15 (2), 140-150.

Kemdiknas. 2009. Pengembangan dan Pendidikan Budaya dan Karakter Bangsa: Pedoman Sekolah. Jakarta: Pusat Kurikulum Balitbang Kemdiknas.

Marzuki, 2012. Pengintegrasian Pendidikan Karakter dalam Pembelajaran di Sekolah. Dalam Jurnal Pendidikan Karakter. 2 (1): 33-44.

Notosusanto, N. 1979. Sejarah Demi Masa Kini. Jakarta: UI Press.

Sugiyono. 2014. Memahami Penelitian Kualitatif. Bandung: Alfabeta.

Suranto. 2015. Teori Belajar dan Pembelajaran Kontemporer. Yogyakarta: Presindo.

Syahrul, N. 2011. Upaya Penyelamatan dan Pelestarian Naskah Kuno Lampung. Jurnal Manassa, 1 (2). 1-16.

Wahyu, A. (Agustus 2016). Perang Suku di Lampung Sebuah Dendam Lama: Kompasiana. http://www.kompasiana.com/perang-suku-di-lampung-sebuah-dendamlama.

Wahyu, E. 2013. Koentara Radjaniti Oentoek Bergoena Atoeran Adat Lampoeng Peminggir, Pubian dan Toelang Bawang. Jakarta: Kementrian Pendidikan dan Kebudayaan.

Widiadi, A. N, dkk. 2013. Pendidikan Sejarah, Suatu Keharusan: Refomulasi Pendidikan Sejarah. Yogjakarta: Universitas Negeri Yoyakarta. 